\title{
Consumer Rights: The case of South Africa and Malaysia
}

\author{
Laura Best \\ Nelson Mandela Metropolitan University, South Africa \\ Peter Cunningham \\ Nelson Mandela Metropolitan University, South Africa
}

\begin{abstract}
As access to the Internet expands across the world, greater numbers of people are buying goods and services on-line, through electronic transactions. In this process, people are disclosing personal data. If this is not effectively protected, a person's right to privacy stands to be violated. This review paper considers the extent to which legislation in South Africa and in Malaysia offers consumers protection when they transact on-line and when they provide personal data in the process, including when using social media sites. It is a reflective piece based on the researcher's personal insights due to more than a decade of experience serving on consumer adjudication statutory structures in South Africa. It is also informed by interviews during visits in December 2012 to Malaysian consumer regulatory offices and non-governmental organizations that focus on consumer protection issues. The findings show that in both countries legislation does not extend far enough to offer consumers redress when they transact electronically. Recently separate legislation for the protection of personal data has been introduced in both countries, and it is thus too soon to assess whether this legislation will be effective. There are initial steps being taken at a geo-political regional level through the Association South East Asian Nations (ASEAN) to encourage individual countries to all establish consumer protection and personal information protection legislation, as well as to promote inter-country co-operation in this regard. The Southern African Development Community (SADC) can learn lessons from this, to take similar steps among member-countries.
\end{abstract}

Keywords: Consumer, consumer rights, laws and structures related to consumers, South Africa, Malaysia, personal information protection

\section{Introduction}

The new global language is electronic technology. It would be hard to find any country at this point in time that does not have mobile phone connectivity. This has brought the world of electronic communication within reach of millions of users. Various studies place global mobile penetration at 85\% (2011) (Ericsson), or as high 
as 96\% (2013) of people around the world now owning mobile phones (Global Mobile Statistic). The percentage of a country's population that use the Internet is also increasing globally, though the extent of usage varies according to geographical region. In South Africa 7.4\% of the population (6.8 million users) is reported as using the Internet, whilst in Malaysia this increases to 36.7\% (17.7 million users)(World Map of Internet Penetration). In the twenty years since the commercialization of Internet services in the 1990s, as of 2011, nearly one third of Earth's population (more than 2.2 billion people) use the services of the Internet. Trends in usage patterns show that as the technological infrastructure improves these numbers are likely to greatly increase. Research also shows that $42 \%$ of mobile phone owners currently have smartphones - and 58\% are planning to make their next mobile phone a smartphone, making the Internet more and more accessible. Internet-based services have been incorporated into virtually every aspect of modern human life. "The Internet has enabled entirely new forms of social interaction, activities, and organizing, thanks to its basic features such as widespread usability and access. In the first decade of the 21 st century, the first generation is raised with widespread availability of Internet connectivity, bringing consequences and concerns in areas such as personal privacy and identity... that were not present for prior generations"(Internet). This is also true for consumer trends, with purchasing of goods and services no longer limited to transactions within a country's geographical boundaries, as e-commerce or the sale of products and services directly via the Web and through mobile phone apps continues to grow.

The Internet and mobile phone technology enable a consumer located in any part of the world to transact with a business located almost anywhere else in the world. Transactions can also constitute a series of actions or steps, each of which can be offered from a different part of the globe. This presents new challenges to governments to provide a regulatory framework for consumer protection within a globally connected business and consumer world. With an increasing range of goods and services available to consumers over the Internet or via mobile phones, crossboundary or trans-border business transactions are becoming the norm rather than the exception. The question then arises as to whether it is possible to create mechanisms for the protection of consumer rights that can be universally applicable in different countries simultaneously, within the context of sovereignty of the respective countries. This can only be achieved through inter-agency co-ordination and interoperability both within a country and between countries, as well as regional and global collaboration through inter-governmental structures.

Concern about data protection has increased worldwide since the 1960 's, alongside the expansion of the technological environment into electronic commerce, and the resultant vast computerised databases of personal information that this has now generated. More recently, and with increasing frequency, social media users disclose personal information when joining and using social media sites. There are different views on the ownership of the content on social media platforms since it is generated by individual users but hosted by a company. Data or information protection forms an element of safeguarding a person's right to privacy. Debates are sharpening around users having a fundamental right to privacy and whether consumer protection policy guidelines could provide redress and remedial action where a person believed they were losing control over their personal information through the actions of a social media site host. This gives rise to the question as to whether a social media user can 
be regarded as a consumer, and the extent to which consumer protection issues come into play in such instances.

\section{Methodology}

The central research problem that this review paper explores is the effectiveness of legislation in South Africa and Malaysia to offer consumers protection when they transact electronically, both within the respective countries and beyond the countries' borders. The paper further questions whether the legislation provides consumers with avenues for redress in such circumstances. In view of the rapidly expanding use of social media sites, including the use of such sites as portals for commercial transactions such as banking, the paper also explores how consumers can take issue and raise complaints when they believe their digitized personal information has been used by an internet-based service provider without their consent, or for purposes for which they did not consent.

This paper provides an exploratory review based on case studies of South Africa and to a lesser extent, Malaysia. It is a reflective piece based on the researcher's personal insights due to more than a decade of experience serving on consumer adjudication statutory structures in South Africa. It is also informed by interviews during visits in December 2012 to Malaysian consumer regulatory offices and non-governmental organizations that focus on consumer protection issues.

The paper will:

Offer initial comments on the legislative frameworks that regulate consumer issues and whether this provides sufficiently for redress in relation to personal information protection and privacy rights in South Africa and Malaysia.

Examine the extent to which these respective regulatory frameworks sufficiently incorporate consumer protection that is responsive to the realities of the digital world and the online environment which is increasingly the arena in which goods are bought and services provided, particularly given that both e-business and social media platforms are global in their reach and usage by consumers.

Drawing on selected international experiences and practices, recommendations are made as to how some of these challenges could be addressed.

\section{Consumer Protection}

The United Nations has issued Guidelines for Consumer Protection (United Nations 1999), which recognize "that consumers often face imbalances in economic terms, educational levels, and bargaining power" and encourages governments to "develop or maintain a strong consumer protection policy" whilst "setting its own priorities for the protection of consumers in accordance with the economic, social and environmental circumstances of the country and the needs of its population". These guidelines are currently under review, as they pre-date the digital age and its related impact on the market place in general and consumer issues in particular. 
In this spirit, the South African and Malaysian governments have both recognised the need to establish a regulatory framework for consumer protection. In the case of South Africa, rights-based consumer protection started to be conceptualised following the first all-inclusive elections in 1994, when for the first time in the country's history, all citizens were entitled to vote and a democratic state came into being. Once the under-pinning policy framework had been settled, the first phase of consumer protection legislation was promulgated in 2005 (the National Credit Act, followed by the Consumer Protection Act). In Malaysia, this happened earlier, with legislation being passed in 1999 (the Consumer Protection Act). There are some notable similarities between the respective legislative architectures, which are discussed below, as both countries attempt to deal with the pressures of democratisation, human rights and the growth of social media issues while simultaneously ensuring they become more globally competitive.

\section{Information Protection and Privacy as a Consumer Issue}

Before setting out an initial comparative analysis of salient aspects of South African and Malaysian consumer protection legislation, it is useful to develop an understanding of how the protection of personal information that is disclosed by consumers when using the Internet - either when transacting commercially or using social media sites - and the related privacy issues connected to the use of and access to this data, have moved to centre stage as a consumer issue.

The protection of personal data has emerged as a key societal concern as social media has grown as a phenomenon, with greater numbers of people embracing and having access to the digital world. It is thus pertinent to consider social media as a construct in itself, but more importantly, how it intersects with consumer protection issues. Social media is at the centre of the changing relationship between people and technology. Social media includes web-based and mobile based technologies which are used to turn communication into interactive dialogue among organizations, communities, and individuals. Kaplan and Haenlein define social media as "a group of Internet-based applications ... that allow the creation and exchange of usergenerated content"(Social Media). Social media is ubiquitously accessible, and enabled by scalable communication techniques. Social media content is generated through social media interactions activated by users through social media sites. There is keen debate on the ownership of the content on social media platforms since this is generated by users yet hosted by the respective social media company. Critics contend that certain of these companies are making money by using content that does not in fact belong to them. The challenge around ownership is less with the content communicated and provided voluntarily by consumers, including the personal data disclosed by the subscribed writers and readers of social media platforms. It is more the parasitic conveying, leaking or selling of agglomerated data to third parties and the privacy implications of this.

Rotenberg (2007) (Director of Computer Professionals for Social Responsibility) commented in an online forum sponsored by the Wall Street Journal: "in the current rush to record and exchange personal data. ...one thing is certain - privacy is an issue whose time has come". 
This is evident in both South Africa and Malaysia, with both countries' governments examining the policy implications with a view to drafting legislation to regulate this. The South African Government tasked the Law Commission to develop proposals in this regard. Its 2009 report "Privacy and Data Protection" (South African Law Reform Commission 2009) indicates that "The growth of centralised government and the rise of massive credit and insurance industries that manage vast computerised databases have turned the modest records of an insular society into a bazaar of information available to nearly anyone at a price... The most important private data users are credit bureaux, transport companies, the health and medical profession, banks and financial institutions, the insurance industry, and the retail and direct marketing industry". Much of this data is provided by consumers when they purchase goods or access services, or apply for credit.

The United States Federal Trade Commission (2012), in its report "Protecting Consumer Privacy in an Era of Rapid Change" notes that "consumers live in a world where information about their purchasing behavior, online browsing habits, and other online and offline activity is collected, analyzed, combined, used, and shared, often instantaneously and invisibly. For example: if you browse for products and services online, advertisers might collect and share information about your activities, including your searches, the websites you visit, and the content you view; or if you participate in a social networking site, third-party applications are likely to have access to the information you or your friends post on the site. Some consumers are troubled by the collection and sharing of their information. Others have no idea that any of this information collection and sharing is taking place. Still others may be aware of this collection and use of their personal information but view it as a worthwhile trade-off for innovative products and services, convenience, and personalization".

This clearly indicates that in today's digital economy, managing consumer information is critically important. This applies to whether a person discloses personal information for the purposes of a business transaction, such as an application for credit; and when a person discloses personal information when using a social media platform. How to manage consumer data has become a central consumer rights issue. The dilemma for governments is to develop regulatory frameworks for personal data protection, and to decide whether to locate this within existing consumer protection legislation or as stand-alone information protection legislation. Either way, thought must be given to the adjudicatory institutional arrangements to give consumers access to redress in the event that they believe their rights have been encroached upon.

The comparative discussion that follows, explores the respective regulatory frameworks in South Africa and Malaysia, with particular reference to the realities of being a consumer in the digital age.

\section{Consumer Protection Legislation}

\section{South African Consumer Protection Legislation}

South Africa has enacted two pieces of legislation as the primary pillars of the statutory framework to regulate consumer matters, namely the National Credit Act (No. 34 of 2005) and the Consumer Protection Act (No. 68 of 2008). These Acts 
jointly institutionalise consumer protection. The National Credit Act (NCA), whilst regulating the marketplace for access to consumer credit, "promotes a consistent enforcement framework relating to consumer credit and establishes the National Consumer Tribunal (NCT)". The Consumer Protection Act (CPA) "promotes a fair, accessible and sustainable marketplace for consumer products and services and for that purpose to establish national norms and standards relating to consumer protection". These Acts have introduced wide-ranging protection for consumers, yet do still have limitations in their scope. Both Acts refer to consumer "rights", however these are not enshrined as fundamental rights in the Bill of Rights in Chapter 2 of the South African Constitution. Given that the Constitution is the supreme law of the country, it needs to be put to an interpretive legal test to determine whether subordinate legislation such as the NCA and CPA can indeed claim to offer rights that are not defined in the Constitution. Until such time, it may be more appropriate to regard South Africans as being beneficiaries of institutionalised consumer protection, rather than having constitutionally guaranteed consumer rights per se.

The NCA provides for protection and a regulated environment when consumers access credit. Otto $(2006,2)$ views the purpose of the NCA as "to protect the average debtor - the person in the street". Importantly, the NCA establishes the National Consumer Tribunal (NCT). Nationally, adjudication of consumer protection is the responsibility of the courts or the NCT, depending on the nature of the issue. Set up in 2006, the NCT's mission is "the provision of accessible adjudication and redress on matters referred to the Tribunal in terms of the National Credit Act and the Consumer Protection Act". It is meant to provide a quicker and less complex avenue for redress than the courts. Accessibility also includes affordability, as a consumer is able to appear unrepresented before the NCT. Otto $(2006,11-12)$ regards the NCT has having "wide powers to make orders in terms of the Act. Its functions are, to a certain extent, comparable to that of a court, but it is not a court as such". Further that "the far-reaching powers of the NCT and the courts, the almost paternalistic protective inclination of the legislature, and the extensive network of dispute solving account for consumer legislation that is going to have a huge impact on the enormous credit industry in South Africa". Otto $(2006,101)$ goes further, stating that "a person who contravenes or fails to comply with an order of the NCT, however, is subject to a fine or imprisonment not exceeding 10 years or both. ... Bearing in mind the pivotal role that the NCT plays, the status that it enjoys in terms of the NCA, and the substantially higher maximum imprisonment sentence prescribed by the NCA, it can be expected that the courts will frown upon a person who does not take the Tribunal's orders seriously".

The CPA was implemented in phases, with full application in October 2010. Consumers have only had a short period to test its ability to offer them advancement and protection of rights. Melville (2010) regards the Act as "one of the best consumer protection acts on the continent (of Africa)", whilst noting that "the Act is a complex legal exposition", presumably because of "the ambiguity or uncertainty of many of the provisions of the Act". The inherent and novel power of the Act requires that the NCT or court develop the common law in such a way that it enables the realization and enjoyment of consumer rights. Specifically, "the Act requires that its provisions be interpreted in a manner that gives effect to its spirit, or the purposes that it intends to achieve. In broad terms this includes: - assisting those who are disadvantaged in terms of income, where they live, age or level of literacy". This potentially 
strengthens the hand of consumers who live in outlying rural areas, and as a result are often disadvantaged by a lack of access to facilities, both to transact and to initiate redress in the event of a consumer complaint. It also raises the question of whether literacy extends to the "electronic illiteracy" of consumers who are now able to transact electronically and access social media, notably through the continuously expanding reach of access through portable mobile technology, specifically mobile phones. These interpretations need to be tested through cases brought before the NCT or the courts for adjudication.

Due to its earlier promulgation, the NCT has adjudicated more cases arising from the NCA than the CPA. These cases have dealt predominantly with various forms of credit agreements between consumers and South African-based credit providers. Most of the cases dealt with by the NCT are consent orders, where a Tribunal member considers and either confirms or refuses the voluntary renegotiation of rescheduled debt payment arrangements, provided these are within the regulatory parameters of the law. An overview of cases dealt with by the NCT since its inception indicates a sharp increase in numbers, from 11 cases in the 2007/08 financial year, to 1382 cases in the 2010/2011 financial year. Specifically, the 2010/2011 financial year saw a $183 \%$ increase in the number of cases (National Consumer Tribunal Annual Report 2011). This trend is continuing as more consumers become aware of how the legislation can assist them with their concerns and predicaments. During 2012, the NCT also began to consider cases related to issues regulated by the NCA, most of which to date relate to conduct within a particular economic sector, such the automobile or telecommunications sectors. Given the nature of cases filed before the NCT, there has been limited scope to test whether the NCA has any applicability to the world of digital commerce and of social media, particularly where a person believes there is a privacy issue at stake.

One means of determining the ability of the NCT to assist consumers who believe that their personal data has been inappropriately used by a social media site, and their privacy compromised as a result, is to examine whether the legal definitions in the Acts regard social media users as consumers. In both instances, the Acts define a consumer in relation to the consumer behaviour that the respective Acts regulate. In the NCA, the definition of a consumer is relational, covering instances where consumers are either party to financial - notably credit - transactions; and/or contract with businesses; and/or purchase goods from enterprises. The CPA offers a four-part definition, of which two components are interesting to consider in relation to the ebased world, and in relation to social media. In the first instance, a consumer is defined as "a person who has entered into a transaction with a supplier in the ordinary course of the supplier's business". Whether or not people "transact" when they use social media, needs to be examined. The second instance opens the definition of consumer more widely, introducing the notion of the "user of particular goods or recipient or beneficiary of those particular services, irrespective of whether that user, recipient or beneficiary was a party to a transaction." This offers a particularly interesting dimension, as the definition may be wide enough to incorporate social media users, and hence regard them as consumers when they access the services of a social media site host.

The question then arises as to whether these two Acts - the NCA and the CPA - offer consumers personal data information protection and also deal with privacy-related 
issues. In the case of the NCA, the legislation does make some provision for privacy issues in prescribed instances, providing for the protection of personal data held by credit bureaux. This Act has no other real applicability to data protection in the social media environment. As mentioned earlier, the potential application of the CPA in the realm of social media rests on how broadly the definition of consumer is interpreted, and this is yet to be tested. The NCT will thus have less of an impact on social media, when adjudicating matters in terms of the provisions of the NCA. There is the possibility of a greater impact under the CPA provisions if adjudicators opt for a wide definitive interpretation with a view to giving "effect to its spirit, or the purposes that it intends to achieve", as argued by Melville. This will be particularly important for rural consumers, many of whom are women and more and more of whom now have the opportunity to transact globally as greater numbers become owners of mobile phones, as the statistics suggest is happening rapidly, and use these to transact electronically.

Thus the South African legislative framework that regulates consumer issues may provide some scope for possible redress in relation to personal information protection and privacy rights, but this would need to be tested during the adjudication of cases of this nature.

\section{Malaysian Consumer Protection Legislation}

The centre-piece of Malaysian consumer protection legislation is the Consumer Protection Act, 599 of 1999 (incorporating all amendments up to January 2006), which establishes the Tribunal for Consumer Claims (TCC). The Act gives consumers rights against suppliers and against manufacturers. The Tribunal provides an alternative channel, other than the courts, for a consumer to file a claim for loss suffered in respect of goods or services purchased or acquired below a certain monetary threshold which is determined periodically. Similar to the intentions of the South African legislation, the primary objective of establishing this Tribunal is to provide an alternative forum for consumers to file claims in an easy, inexpensive and speedy manner. It thus locates redress alongside the formal judicial system, recognising that court proceedings are often lengthy and require the services of a legal representative, which carries financial costs often unaffordable to consumers, or which is such that this outweighs the cost of possible redress payable to a consumer.

The Malaysian Act defines a consumer as "a person who acquires or uses goods or services of a kind ordinarily acquired for personal, domestic or household purpose, use or consumption”. Consumer issues are thus framed around a transactional relationship between a consumer and a business, which is similar to the South African NCA conceptualization of the definition of a consumer. The TCC is cognisant that consumers are now entering into Internet transactions, cautioning consumers "before joining any transaction activity via the Internet, think wisely as its high risk, said Mohd Khalis Kasim, the Deputy Director of Domestic Trade, Co-operatives and Consumerism" (Yassop, 2011). The TCC does not take this further, to indicate whether use of a social media site constitutes a transaction or to advise consumers to exercise similar caution when signing up to be able to interact on social media sites. Again, it needs to be determined whether the Malaysian legislation offers a definition of a consumer that is able to incorporate social media users. Initial reading may 
suggest that this is indeed the case in that a person could "acquire" social media "services for personal use", and as such these activities would fall within the scope of the Malaysian CPA. However, reading further into the Act, section 2(2) specifically limits the TCCs jurisdiction, to exclude "any trade transactions effected by electronic means unless otherwise prescribed by the Minister". Thus despite the fact that "a consumer may lodge a claim with the Tribunal claiming for any loss suffered on any matter concerning his(her) interests as a consumer arising from, amongst others, a false or misleading conduct, false representation or unfair practice", and which such practice may have been undertaken by a social media services provider, both the transactional basis of the definition of "consumer" and the specific jurisdictional limitation regarding electronic transactions, suggests that the TCC will be unable to assist consumers with complaints against social media service providers. It would be interesting to explore further if it would be possible to avoid the jurisdiction limitation by arguing that use of a social media site is not a "trade" transaction, and therefore the TCC does in fact have jurisdiction in such instances.

Despite the legislative limitations imposed on the TCC to provide assistance to consumers with complaints regarding electronic transactions, the TCC has shown innovation in incorporating the use of mobile technology in its own business processes and communication with users of its services. In-so-doing, it has allowed for experimentation with e-communication and social media-related issues in its own communication with consumers who approach the TCC for assistance. Specifically, a consumer is able to initiate lodging a complaint with the TCC by means of sending an SMS (Pretam 2011) from their mobile phone. This offers consumers the convenience of seeking redress from any location, at any hour of the day, and at minimal cost. It will be interesting to explore whether this experience is prompting them to consider proposing legislative amendments to extend their jurisdiction to electronic transactions by consumers. The South African NCT could learn important lessons for its own business processes from the TCC, about how to use mobile phone technology to expand access to its services, particularly for rural consumers, who are now increasingly likely to own mobile phones. 
Table (i) below summarizes the key comparative elements of South African and Malaysian consumer protection legislation that are the subject of discussion in this article.

Table (i): Comparative elements of South African and Malaysian consumer protection legislation

\begin{tabular}{|c|c|}
\hline South Africa & Malaysia \\
\hline $\begin{array}{l}\text { National Consumer Tribunal } \\
\text { - Formal adjudication: } 2 \text { Acts } \\
\text { - Consumer approaches Consumer } \\
\text { Commission for direct dispute } \\
\text { resolution \& redress, rather than the } \\
\text { Tribunal } \\
\text { - Can adjudicate credit matters }\end{array}$ & $\begin{array}{l}\text { Tribunal for Consumer Complaints } \\
\text { - Formal dispute resolution: } 1 \text { Act } \\
\text { - } \text { Consumer and seller appear directly } \\
\text { before TCC } \\
\text { - No powers relating to credit matters }\end{array}$ \\
\hline $\begin{array}{l}\text { Consumer Definition } \\
\qquad \quad \text { Entered transaction with supplier } \\
\text { - } \quad \text { User of goods and services }\end{array}$ & $\begin{array}{l}\text { Consumer Definition } \\
\text { - Acquires goods and services } \\
\text { - } \quad \text { Personal or household use }\end{array}$ \\
\hline $\begin{array}{l}\text { Electronic Transactions } \\
\text { - Regulated under the Electronic } \\
\text { Communications and Transactions } \\
\text { Act, not NCA or CPA }\end{array}$ & $\begin{array}{l}\text { Electronic Transactions } \\
\text { - CPA excludes: "Any trade } \\
\text { transactions effected by electronic } \\
\text { means unless otherwise prescribed } \\
\text { by the Minister" }\end{array}$ \\
\hline $\begin{array}{l}\text { NCT Jurisdiction } \\
\text { - South Africa }\end{array}$ & $\begin{array}{c}\text { TCC Jurisdiction } \\
\text { - Malaysia }\end{array}$ \\
\hline
\end{tabular}

Despite both countries laws being developed at a time when Internet connectivity was on the rise, the preliminary overview explored above indicates that neither have sufficiently incorporated consumer protection within the context of an increasingly digitized e-commerce, e-business and social media market-place. Initial indications from the comparative overview provided above, suggest that consumer protection legislation in both Malaysia and South Africa has limitations in providing a regulatory safety-net when consumers transact electronically, notably when this is trans-border, and also when using social media sites. These limitations centre around jurisdictionality and restrictive definitions under which circumstances a person can be regarded as a consumer. Both sets of consumer legislation also have limited powers to protect and regulate consumers personal information. Rather, it would seem that both countries are putting in place personal data protection legislation to assist consumers, as discussed below.

\section{Personal Data Protection Legislation}

This section will address the extent to which personal data protection regulatory frameworks sufficiently incorporate consumer protection that is responsive to the realities of the digital world. This is because the online environment is increasingly the global arena in which goods are bought and services provided. 
Personal data or information protection legislation has greater effect and is more easily enforceable when this rests on constitutional protection of the right to privacy. In South Africa the right to privacy is protected in terms of both the common law and in the Bills of Rights in section 14 of the Constitution. This recognition and protection of the right to privacy as a fundamental human right in the Constitution provides an indication of its importance. Similar to South Africa, the Malaysian Constitution is the supreme law of the land, which sets out "fundamental liberties". Recent case law (Federal Court case of Sivarasa Rasiah v Badan Peguam Malaysia \& Anor [2010] 3 CLJ 507 at 519) has established that the Constitution recognises the right to privacy under Article 5 which provides that "No person shall be deprived of his life or personal liberty save in accordance with law." According to Gopal Sri Ram FCJ, in the Sivarasa case, "the right to personal liberty includes the right to privacy" (Privacy International 2012).

On this basis of this, Leong (2011) argues that "the recognition of right to privacy in Sivarasa's case may be a stepping stone to the expansion of the tort of breach of confidence to include "misuse of private information", Further that "if the tort of invasion of privacy or misuse of private information is recognised in Malaysia, this may be used as a remedy against those who had breached the Malaysian Personal Data Protection Act 2010".

With the advent of the Personal Data Protection Act 2010 ("PDPA"), Malaysia will have, for the first time, privacy-specific legislation. "The key objective of the PDPA is to regulate the processing of personal data by data users in the context of commercial transactions, with the intention of safeguarding the data subject's interest. Cross-border transfer of personal data will also be regulated. The PDPA specifies that no transfer of personal data outside of Malaysia can occur unless the place has been specified by the Minister of Information, Culture and Communications. In determining this, the country to which personal data is transferred to must possess an adequate level of protection which is at least equivalent to the level of protection afforded by the PDPA. A number of advisory, regulatory and enforcement bodies are also due to be established pursuant to the PDPA. Apart from the Personal Data Protection Commissioner, the Personal Data Protection Fund, the Personal Data Protection Advisory Committee and the Appeal Tribunal will also be established". The Bill was passed by the Malaysian Parliament in early May 2010, yet was only enacted in 2013. Is perhaps indicative of the complexity of implementing the provisions of the Act?

In South Africa, guided by the findings in the Law Commission Report "Privacy and Data Protection", as discussed above, the Protection of Personal Information Act (POPIA) has finally been considered in the national Parliament. Currie notes that "POPIA is purpose-specific privacy and data protection legislation, and is an important legal reform, creating a regime of consumer protection that has become essential in the information age. It is data protection legislation, intended to protect individuals from detriment resulting from the processing of information about them". Civil rights groupings have lobbied extensively to ensure that POPIA provides the appropriate balance between the protection of personal information and freedom of information. The Act establishes a juristic person, the Information Protection Regulator, with responsibility, amongst others, to monitor and enforce compliance by 
public and private bodies of the provisions of the Act. The Regulator may also receive and investigate complaints about alleged violations of the protection of personal information of data subjects, and may issue codes of conduct. POPIA makes broad reference to collaboration with other national bodies that regulate the management of personal information, such as the information collected and managed by credit bureaux in terms of the National Credit Act. It states that POPIA provisions do not affect the operation of any other legislation that regulates the processing of personal information and is capable of operating concurrently. The explanatory memorandum accompanying the Bill to Parliament further indicates that those provisions dealing with the investigation of complaints by the Regulator include "the power to refer a complaint to another regulatory body if such regulatory body is in a better position to deal with the complaint". This implies that the NCT would be in a position to consider complaints within its legislative mandate, such as those related to personal information in credit bureaux data-bases. However, any real benefit for consumers will depend on a seamless and co-operative interface between the NCT and the proposed Information Protection Regulator.

POPIA received the attention of both the executive and legislative arms of government for a considerable period of time. This protracted process to arrive at enactment of personal data protection legislation in both countries is surely indicative of the complexities of this issue, despite its ever-increasing impact on the lives of consumers. It will be interesting to see what eventually pans out in practice, now that both the South African and the Malaysian legislation have now become law. Of particular interest will be in relation to personal information that is up-loaded voluntarily onto social media websites, and whether the NCT is able to establish that this activity falls within the definition of a consumer according to the CPA, and is thus within the regulatory ambit of the NCT. Alternatively whether the scope of POPIA is wide enough to provide redress to social media uses who believe their personal data has been mis-used or mis-appropriated, and their privacy compromised as a result.

Similar to the Malaysian legislation, POPIA sets out conditions under which the transfer of personal information outside the borders of South Africa is permissible. These intentions are laudable. However, if trans-border information flows are to be successfully regulated, legislative implementability will need to rely heavily on international co-operative agreements and inter-agency collaboration. In the first quarter of 2012, the Association of South East Asian Nations (ASEAN) region has placed privacy developments onto its agenda, encouraging member states to develop personal information protection Bills. These are currently being drafted in the Philippines and Singapore, with Malaysia having now adopted its legislation. The inter-operability of these frameworks will be interesting to observe, and may provide lessons for the Southern African Development Community (SADC) region, where there has been limited regionally-based developments concerning privacy.

\section{Reflections and Looking Ahead}

Having considered the respective legislation in South Africa and Malaysia that provides consumers recourse in instances when they believe they have not been treated in the appropriate manner, it is useful to offer comparative reflections, and to 
sketch out areas that should receive the renewed interest of policy makers. The researcher's observations are the following:

In both countries, consumer protection legislation does not go far enough to definitively incorporate the regulation of consumer protection for transactions in the world of e-commerce in general, and when a consumer is active in the social media environment in particular

$\square$ On the other hand, though personal data information protection is clearly of central interest to consumers in the rapidly evolving digitized world, both countries have opted to set up stand-alone regulatory frameworks to manage this complex issue, rather than frame this within the context of consumer protection legislation

$\square$ Both countries have further located personal information protection within the paradigm of the right to privacy. The constitutional status of this right in both countries, is advantageous in this respect, as neither country provides for the constitutional protection of consumer rights

$\square$ The concurrent regulatory frameworks for consumer protection and personal data information protection mean that the ability of both realms of legislation to be implemented in the interests of consumers will depend on mutual corecognition by the respective regulatory and adjudicatory bodies, and the establishment of clear protocols to create a seamless intersection of functionality

Legislation will by its nature remain limited as a tool to respond to the transborder nature of e-transactions, as well as the geo-boundary-less-ness of social media interactions by consumers. Due to the sovereign applicability of legislation, this will perhaps always be the case. In addition to national legislation, consumer protection regulatory frameworks will need to be negotiated as a component of regional protocols and trade agreements.

$\square$ Effective inter-country enforcement will remain dependent on international co-operation between regulatory agencies charged with implementing these protocols. These will always be subject to the vagaries and fluidity of geopolitical forces constantly at play, and consumer concerns will be subservient to this.

In conclusion, the interface between personal data privacy protection legislation and consumer protection legislation, is set to become of increasing relevance and importance to consumers. In both South Africa and Malaysia, more thought will need to be given to defining this interface, and in particular, whether the respective Consumer Tribunals could or should have a role to play in the regulation and adjudication of such cases. The area which stands out most starkly as deserving consideration by policy makers and consumer rights advocacy organizations, is how to frame the relationship between social media users and the hosts of such sites. Are social media users consumers, and if so, how do regulatory frameworks need to be reconfigured to incorporate this? Alternatively, do social media users relate in a purely personal capacity with site hosts, and as such constitute a form of "digital voluntary association" that should by its very nature remain unregulated? A first step in beginning to engage with this potential conundrum may be to undertake an analysis of the privacy clauses which most social media sites require potential users to agree to before they are allowed to become a registered user. It is certainly common cause that most users surely click the "agree" button with perfunctory alacrity, in order to be given access to social media inter-activity. The extent to which consumers forego 
important pre-emptive protection of usage of their personal information, and related implications for privacy considerations, will offer useful insights to policy-makers for assessing whether regulatory frameworks can indeed protect consumers in this digital space.

What remains most critical, is for consumer interest groups to continue to lobby policy makers to ensure that regulatory frameworks are revised to incorporate digital transactions, both domestically and at regionally, within the ambit of inter-country trade agreements.

South Africa and Malaysia can learn from each other as the two countries begin to implement their respective legislation to protection personal information. The SADC also stands to benefit from the ASEAN regional initiative to encourage member states to implement personal information protection legislation and to put in place cooperative inter-country agreements when consumers trade cross-boundary. The two regional bodies may also consider discussions to put in place inter-regional consumer protection mechanisms as trade between the two regions expands, as global cooperation between regional inter-governmental structures is necessary if consumer rights in the digital world are to become implementable.

\section{Implications for Business Marketing Practice}

Marketing practitioners play an important role in providing consumers with information about goods and services that are available in the market. This in turn helps consumers make decisions about how they choose to spend their money and which products they choose to buy. Responsible marketing practices dictate that this information is provided in a manner that recognises that consumers have rights to fair practices from producers and that there are consequences if these are not adhered to by service providers. Marketing practitioners need to be aware of the prevailing legislation to ensure that they operate within this and at the same time integrate this into their communication messaging for consumers. Similarly, practitioners need to sensitize providers of goods and services of the regulatory frameworks that offer consumer protection and that they thus need to heed in their business practices.

As the sale of goods and services migrates to digital platforms, this shapes practices in business marketing. The implications of consumer transactions in this environment raise interesting new dimensions that impact on marketing practice. It is thus important that this is incorporated into communication strategies designed by marketers.

\section{References}

Asian Committee on Consumer Protection. (2011), Types of Claims that May be Brought Before the Tribunal. Retrieved Aug 31 2012, from http://www.aseanconsumer.org/claims/malaysia/typesofclaims/ 
Consumer Protection Act, 1999. (Act 1999 No. 599 of 1999) Laws of Malaysia. Retrieved July 25 2012, from http://aseanconsumer.org/misc/downloads/miscmsiacpa.pdf

Currie, I. The Protection of Personal Information Act and its Impact on Freedom of Information. University of the Witwatersrand, Johannesburg. Retrieved August 7 2012,from http://www.opendemocracy.org.za/wpcontent/uploads/2010/10/The-Protection-of-Personal-Information-Act-and-itsImpact-on-Freedom-of-Information-by-Iain-Currie.pdf

Ericsson. (November 21 2011), Middle East Mobile Penetration Rate Higher Than Global Average. Retrieved September 17 2012, from http://www.ameinfo.com/281819.html

Global Mobile Statistic. (2013), Retrieved August 15 2013, from http://mobithinking.com/mobile-marketing-tools/latest-mobile-stats

Internet. Wikipedia: The free encyclopedia. FL: Wikimedia Foundation, Inc. Retrieved August 10, 2012, from http://en.wikipedia.org/wiki/Internet

Ismail, N. Selected issues regarding the Malaysian Personal Data Protection Act 2010. International Data Privacy Law Advance Access. March 28 2012. Retrieved from

http://idpl.oxfordjournals.org/content/early/2012/03/28/idpl.ips005.abstract

Ismail, N. Selected issues regarding the Malaysian Personal Data Protection Act 2010. International Data Privacy Law Advance Access. Mar 28 2012. Retrieved from

http://idpl.oxfordjournals.org/content/early/2012/03/28/idpl.ips005.abstract

Leong, FC. (2011). Right to privacy in Malaysia: Do we have it? Retrieved September 32012 from http://www.loyarburok.com/2011/02/21/right-to-privacy-inmalaysia/

Melville, NJ., (2010) The Consumer Protection Act Made Easy, (2 ${ }^{\text {nd }}$ Edition).

National Consumer Tribunal Annual Report 2011. Retrieved May 30 2012, from http://www.thenct.org.za/NCTDocs/annual-reports/546b3322-6b93-4a16a502-9f6a9117933d.pdf

National Credit Act, 2005. (Act No. 34 of 2005) Government Gazette. Retrieved July 6 2013, from http://www.thenct.org.za/NCTDocs/foundinglegislation/9a669fbc-ef58-4bd2-8a5e-d12f37d018bf.pdf

Otto, JM., (2006), The National Credit Act Explained, (3 ${ }^{\text {rd }}$ Edition). LexisNexis.

Pretam, S. Consumers can file claims via SMS. Borneo Post Online. (27 July 2011). Retrieved August $\quad 6 \quad 2012, \quad$ from http://www.theborneopost.com/2011/07/27/consumers-can-file-claims-viasms/ 
Privacy International. (2012). Chapter: II: Legal Framework. Privacy International. Report: Malaysia. Retrieved September 32013 from http://privacyinternational.or/reports/malaysia/

Protection of Personal Information Bill. Republic of South Africa. Retrieved September 16 2013, from http://www.justice.gov.za/legislation/bills/B92009_ProtectionofPersonalInformation.pdf

Rasiah, S. v. Malaysia, BP \& Anor. 20103 CLJ. Retrieved September 3 2012, from http://www.themalaysianinsider.com/

Right to Privacy in Malaysia: Do we have it? Retrieved September 15 2013, from http://xes.cx/tag/sivarasa-rasiah-v-badan-peguam-malaysia-anor/

Rotenberg, M. (June 2007), Retrieved August 17, 2012, from http://online.wsj.com/article/SB118212400791838498.html?mod=2_1305.htm - 3

Social Media. Wikipedia: The free encyclopedia. FL: Wikimedia Foundation, Inc. Retrieved August 17, 2013, from http://en.wikipedia.org/wiki/Social_media

South African Law Reform Commission. Privacy and Data Protection Report. (Project 124. 2009). Retrieved March 15 2012, from http://www.justice.gov.za/salrc/reports/r_prj124_privacy\%20and\%20data\%20 protection2009.pdf

The Consumer Protection Act, 2008. (Act No. 68 of 2008). Department of Trade and Industry. $\quad$ Retrieved May 31 2012, from http://www.info.gov.za/view/DownloadFileAction?id=99961

United Nations. Economic and Social Council. (July 26 1999). $2^{\text {nd }}$ Plenary Meeting. United Nations. www.un.org/esa/sustdev/publications/consumption en.pdf

United States Federal Trade Commission. Protecting Consumer Privacy in an Era of Rapid Change. Federal Trade Commission Report. (March 2012). Retrieved 3 June 2013, from http://www.ftc.gov/os/2010/12/101201 privacyreport.pdf

World Map of Internet Penetration. Retrieved September 6 2013, from http://www.kwintessential.co.uk/map/internet-penetration.html

Yassop, Y. Use tribunal for redress, consumers urged. The Borneo Post. (23 Feb 2011). 